\title{
American Water Spaniel
}

National Cancer Institute

\section{Source}

National Cancer Institute. American Water Spaniel, NCI Thesaurus. Code C53880.

The American Water Spaniel is an active, muscular and hardy dog with a broad skull. It has a crisp-textured, tightly curled or wavy outer coat lined with a protective undercoat. Coat colors can include liver or chocolate. Height: 15-18 inches (36-46 cm.) Weight: 2545 pounds $(11-20 \mathrm{~kg}$.) 